\title{
Chanceaux-Sur-Choisille, Prairie de la Bourdillière
} $n^{\circ} 067853$

Anne-Marie Jouquand et Roland Irribarria

\section{(2) OpenEdition}

\section{Journals}

Édition électronique

URL : http://journals.openedition.org/adlfi/13753

ISSN : 2114-0502

Éditeur

Ministère de la culture

Référence électronique

Anne-Marie Jouquand et Roland Irribarria, «Chanceaux-Sur-Choisille, Prairie de la Bourdillière », ADLFI. Archéologie de la France - Informations [En ligne], Centre, mis en ligne le 28 octobre 2014, consulté le 24 avril 2019. URL : http://journals.openedition.org/adlfi/13753

Ce document a été généré automatiquement le 24 avril 2019

(C) Ministère de la Culture et de la Communication, CNRS 


\title{
Chanceaux-Sur-Choisille, Prairie de la Bourdillière
}

$n^{\circ} 067853$

\author{
Anne-Marie Jouquand et Roland Irribarria
}

Lien Atlas (MCC) : http://atlas.patrimoines.culture.fr/atlas/trunk/index.php?

ap_theme=DOM_2.01.02\&ap_bbox $=0.662 ; 47.452 ; 0.748 ; 47.500$

1 Cette nouvelle intervention de diagnostic sur le site de Chanceaux-sur-Choisille a révélé des occupations de 3 périodes pré- et protohistoriques. La plus ancienne se rapporte au Villeneuve-Saint-Germain tardif de style Augy, période extrêmement mal connue (aucun grand site d'habitat fouillé), et qui, dans notre région, établit la transition entre Néolithique ancien et le Néolithique moyen 1. Ce dernier est également présent sur le site à l'est du chemin communal. Les 4 fragments d'un même vase Chambon aux tranches non usées sont en position secondaire dans une fosse Hallstattienne, ce qui suggère le bris de ce vase sur place et un déplacement à courte distance avant son recouvrement. Ce vase s'ajoute aux découvertes ponctuelles effectuées dans la région comme celles de Lublé (1 vase), de Neuvy-le-Roi (1 vase à ouverture quadrangulaire), de Sonzay (3 vases) et de Breil (1 vase). Un peu au sud-est de Tours, 3 sites d'habitats sont connus à Esvres, Truyes et à Amboise. On constate donc une occupation importante de ce groupe dans la région.

2 Enfin, une occupation du $1^{\text {er }}$ age du Fer a été mise en évidence par une fosse et un alignement de poteaux qui suggère la présence d'un habitat structuré. Cette période est également mal connue en région Centre où peu d'habitats ont été fouillés

Il semble aujourd'hui possible d'identifier les vestiges observés sur le site de la prairie de la Bourdillière comme ceux d'une vaste villa gallo-romaine plutôt que d'une agglomération secondaire antique. La faible densité des structures et leur dispersion sur une grande surface indiquent qu'il s'agit d'un grand domaine. Ces éléments épars prennent leur place dans une étude générale de cette exploitation. Il s'agit d'un ensemble cohérent. On rappellera que toutes les structures mises au jour en 1997 sont extrêmement arasées, voire partiellement détruites. L'étude antérieure a montré que les vestiges bâtis 
en pierre, en particulier la partie thermale qui comprend des aménagements excavés (bassins), sont quant à eux relativement bien conservés. L'emprise concernée par cette évaluation, large de $120 \mathrm{~m}$, recoupe une partie de ces aménagements.

INDEX

operation Évaluation archéologique (EV)

Index géographique : Centre, Indre-et-Loire (37), Chanceaux-sur-Choisille

Mots-clés : villa, vase

Index chronologique : Néolithique, âge du Fer 